\title{
DESIGN AND IMPLEMENTATION OF IN-HOUSE CURRENCY SYSTEM TO FOSTER MUTUAL ACTIONS
}

\author{
Toshiomi Moriki ${ }^{1}$, Hiroki Satoh ${ }^{1}$, Shinpei Takami ${ }^{1}$, Kie Yoshiji ${ }^{1}$, Miho Kobayashi ${ }^{1}$ \\ and Norihisa Komoda ${ }^{2}$ \\ ${ }^{1}$ Research \& Development Group, Hitachi, Ltd., 1-280, Higashi-koigakubo Kokubunji, Tokyo 185-8601, \\ Japan \\ ${ }^{2}$ Code Solutions, Co.,Ltd., 1-2-11-9F Edobori Nishi-ku, Osaka, Osaka 550-0022, Japan
}

\begin{abstract}
With the pandemic of a new type of infectious disease, people are trying to shift to a new way of working, mainly by working from home. To address the concerns of remote work, such as poor communication among employees and loss of a sense of self-efficacy, the authors have designed and developed an in-house currency system that promotes mutual aids among employees. The system is implemented mainly on a cloud system and is accessed by employees as a web application on their smartphones. This in-house currency application accepts reports of mutual aids behavior and provides a small monetary incentive. It also has a user interface that fosters empathy by visualizing the mutual aid behaviors of employees to all participants. This system has been implemented on a trial basis for our R\&D department, and employee participation is evaluated over a year. During the test period, in addition to daily mutual aid activities among employees, the activities that promoted actions among employees are observed. User interviews indicate that the in-house currency system is effective in stimulating communication among employees and strengthening their sense of self-efficacy.
\end{abstract}

\section{KEYWORDS}

In-House Currency System, Mutual Assistance, Engagement Measurement

\section{INTRODUCTION}

The global outbreak of infectious diseases that began in early 2020 has forced all business people and citizens, for-profit as well as non-profit organizations, to explore new ways of living and working. The enforcement of urban lockdown policies mainly in China, the UK, and Australia, as well as the request for private companies in Japan to reduce the rate of work attendance, are fresh in our minds. In addition to maintaining social distancing during 
IADIS International Journal on WWW/Internet

face-to-face meetings, working from home (WfH), a form of non-face-to-face employment is now being encouraged. WfH seems to be widely accepted in intellectual labor-intensive occupations such as programmers and system developers and research and planning departments.

On the other hand, the negative effects of WfH have also been pointed out (Wang, B., et al, 2021). The boundary between work and private life becomes blurred (Nishida, Y. and Terashima, N., 2019), leading to long working hours and so-called "Zoom fatigue"(Morris B., 2020). Unlike when a large number of employees work in the same office, there is a lack of communication such as casual chatting, making communication difficult. Inappropriate labor management is also a factor, resulting in a decline in employee engagement. The turnover rate would increase, among other negative effects. In order to overcome these negative effects, solutions using ICT tools have been explored, including the introduction of business chats such as Teams ${ }^{1}$, (Slack, 2018), and the fostering of salon-like chats using Spatial Chat ${ }^{2}$.

As one of the measures to improve employee engagement through ICT tools, the introduction of an in-house currency has been attempted. An in-house currency is a type of reward system that improves employee engagement by promoting a positive culture within a company, such as interaction and mutual help among employees (Tamura, K., 2018). Unlike legal currency issued by the government or frequent flyer points used for sales promotion in the private sector, the in-house currency is a special-purpose currency that is accepted only within a specific organization. It provides small monetary incentives to employees for activities that the human resources (HR) department or the administrative and general affairs department deems desirable in terms of corporate operations, in addition to the regular salary for employees. The monetary incentives are paid for internal activities that foster mutual aid activity and communication among employees, and CSR (Corporate Social Responsibility) activities such as volunteering for local communities.

An example of an in-house currency system used in the R\&D department, where the majority of employees are intellectual workers is introduced (Moriki, T., et al, 2021). The paper shows the usage history of the in-house currency system. Also, the activation of the communication among employees by the system is discussed.

New topics discussed in this paper are the service framework of the in-house currency system, the design of the user interface for both employees and system managers. And the implementation of the in-house currency system is described, which includes its architecture on the cloud and REST interfaces, main DB data structures. In the trial of the system, this paper shows the usages of the system during the trial period under the COVID-19 pandemic and the results of user interviews.

\footnotetext{
${ }^{1}$ https://docs.microsoft.com/en-us/microsoftteams/teams-overview

${ }^{2}$ https://spatial.chat/
} 


\section{THE IN-HOUSE CURRENCY SYSTEM AND ITS CHALLENGES}

\subsection{Overview of the In-House Currency System}

The in-house currency is a private currency that circulates only within a specific organization. The in-house currency is issued by a company's Human Resources (HR) department or General Affairs department and is expected to promote desirable behaviors such as increased productivity and smoother organizational operations among employees and workers in the organization.

In recent years, the in-house currency has been used for a variety of purposes, such as improving work performance by promoting communication among employees and supporting other employees in performing their duties, as well as participating in off-the-job activities such as local volunteer activities and efforts to improve the global environment.

Table 1 shows the types of in-house currency systems. In this study, following both functions will be included.

(1) Incentives to encourage favorable behavior from the company to the employees: Incentive program type

(2) Message function to express gratitude for mutual help among employees: Peer bonus type

Table 1. Types of In-house Currency System

\begin{tabular}{l|l|l}
\hline Type & Description & $\begin{array}{l}\text { The direction of } \\
\text { currency flow }\end{array}$ \\
\hline \hline (1) Incentive Program & $\begin{array}{l}\text { Rewards from the company to employees to encourage } \\
\text { positive behavior. }\end{array}$ & $\begin{array}{l}\text { Company to } \\
\text { employee }\end{array}$ \\
\hline (2) Peer Bonus & $\begin{array}{l}\text { A messaging function to express appreciation among } \\
\text { employees for helping each other. }\end{array}$ & $\begin{array}{l}\text { Employee to/from } \\
\text { employee }\end{array}$ \\
\hline
\end{tabular}

Figure 1 shows a brief diagram of the entire in-house currency system. The service provider of the in-house currency is the company itself. The in-house currency service is offered via a mobile application on the smartphone. The in-house currency is issued as a financial incentive to employees by the HR department through (1) incentive program. Employees will report on their work or non-work activities daily basis. It is also sent to each other as a (2) peer bonus between employees and is used as a means to express empathy and appreciation for each other's mutual action.

The company currency earned by employees can be used as a means of payment in the company cafeteria and stores. Cafeterias and concession stands (often outsourced to the 3rd party company) will generate invoices based on the payment in the in-house currency and will send them to the HR department for settlement. 


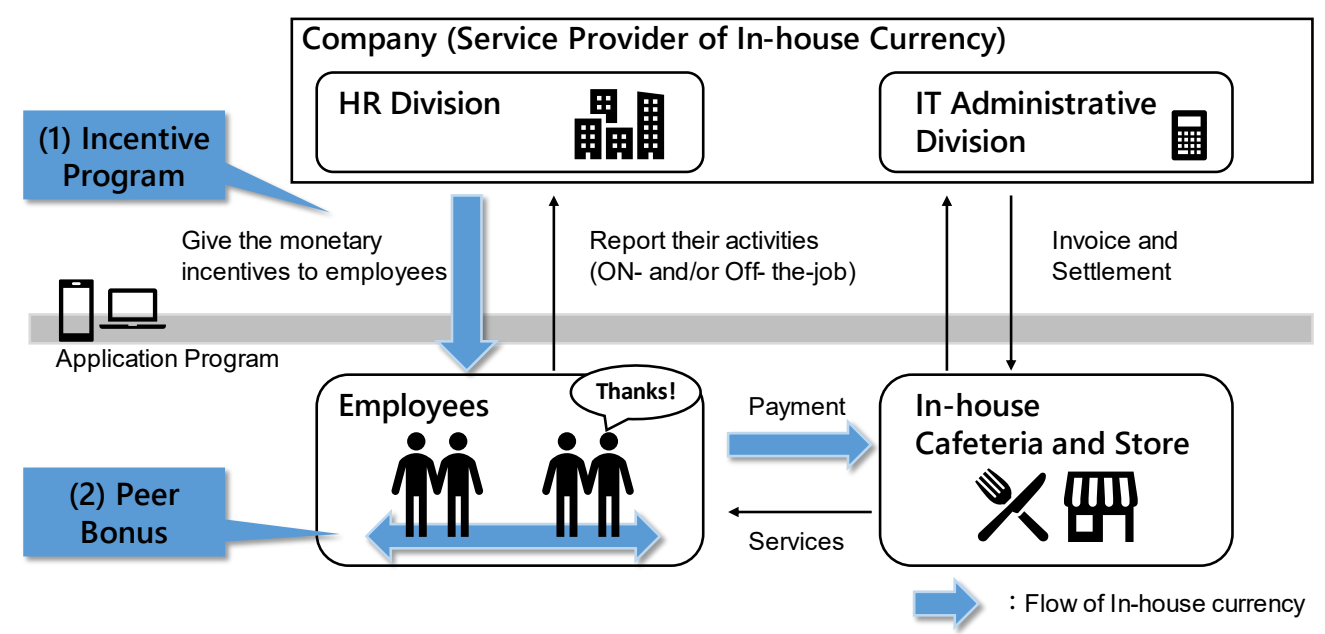

Figure 1. Service framework of the In-house Currency System

\subsection{Challenges in Promoting the use of In-House Currency Systems}

In this section, the implementing issues of an in-house currency system are discussed. Table 2 shows a list of issues to be considered in order to increase the number of users who use this system on a daily basis (i.e., active users).

(a) Regarding the low threshold for starting to use the system, many people said that it would be good if there was some kind of mechanism to encourage participation from the company side. Specifically, it would be desirable if the work line of the employee's supervisor recommends participation, or if the benefits of participation are clearly stated for individual employees.

(b) It is difficult to devote a lot of time and effort to programs related to the in-house currency system because it is different from the main business. It is desirable to make it as easy as possible for novices to use the system in order to prevent them from leaving.

(c) Considering that it is a means of communication among employees, it is desirable to be able to see at a glance that others are using it even in a remote environment. It is also good to have an incentive to involve other employees.

Table 2. Issues in implementing an in-house currency system

\begin{tabular}{l|l|l}
\hline$\#$ & Issues & Description \\
\hline \hline (a) & $\begin{array}{l}\text { Barriers to involve } \\
\text { new users }\end{array}$ & $\begin{array}{l}\text { They need a good mechanism to encourage participation. Participation } \\
\text { should be encouraged via command channel, the benefits of } \\
\text { participating as an individual are easy to understand, etc. }\end{array}$ \\
\hline (b) & $\begin{array}{l}\text { Difficulties to } \\
\text { continue to use the } \\
\text { app }\end{array}$ & $\begin{array}{l}\text { Since the program is different from the main task, it should be as easy to } \\
\text { use as possible. }\end{array}$ \\
\hline (c) & $\begin{array}{l}\text { Challenges of } \\
\text { sharing } \\
\text { activities }\end{array}$ & $\begin{array}{l}\text { It is desirable to be able to see at a glance that other people are using it, } \\
\text { even in a remote environment. It is better if there is an incentive to } \\
\text { involve other employees. }\end{array}$ \\
\hline
\end{tabular}


The following are service policies to deal with the above issues and to increase the number of active users.

(a) Easy to enter: The service is announced to all employees on the company's intranet, and a permanent guide is posted in the prominent place. Employees are recommended to use nicknames instead of their real names, assuming that they are highly sensitive to others' opinions and privacy.

(b) Easy to use: Implemented as a mobile web application that does not require the installation of any application as a touchpoint for users.

(c) Easy to spread to others: In order to feel the mutual activities of other users even in non-contact situations such as working from home, users can observe the timeline of all users' mutual actions reported, peer bonus sympathy, and the currency. In addition, the time-limited reward programs are provided to acquire new users.

\section{DESIGN AND IMPLEMENTATION OF THE IN-HOUSE CURRENCY SYSTEM}

In designing the in-house currency system, the following two types of users have been assumed.

(1) General users (employees): They access the in-house currency system via smartphones. They need intuitive understanding, easy operability, and UI (User Interface) design that promotes interaction among employees.

(2)

(3) Administrative users (HR department, system administrators): They access mainly via a web browser on PC (Personal Computer). They need to manage general user accounts properly and operate campaigns to promote volunteer activities.

\subsection{The Functions and UI Design for General Users}

In designing the In-house currency system, the unit of the incentive is named "THX." It is pronounced the same as "Thanks" in order to remind users that mutual help and behaviors are important for themselves as well as for the company. For easy understandings, 1 THX is treated as the same value of 1 JPY (Japanese Yen) of legal tender.

The HR division of the company issues the THX values for users who report mutual actions, which called in this system "ACT." The typical issuance amount for an ACT is 39 THX on daily basis, which is the same quantity pronounced in Japanese as "Thank You."

(1) The functions and UI design for general users are shown in Figure 2. The following functions are provided for general users: (i) user registration, (ii) ACT reporting, (iii) ACT sharing and reaction, (iv) QR code payment, and (v) user account management. 
IADIS International Journal on WWW/Internet

(i) for user registration, the user shall set the company email address, contact email address, nickname, and password on the dedicated user registration page. From then on, when using this application and interacting with other users, users can communicate using only their nicknames without using their real names or employee numbers. This is "easy to enter": to reduce the barriers for users to use this application, and to allow them to interact with other users without feeling the barriers between business activity and personal life.

In the event of an invitation from another user, both the user and the inviter will receive additional THX points by setting the inviter's email address.

An email will be sent to the registered email address with the URL of the login page. On the login page, the user enters the registered email address and password, and the user will be forwarded to the front page of the app. Once the password is entered, the login information (credential) holds valid status for the next 30 days, saving the user the trouble of logging in each time. The user credentials are kept safe on the mobile web browser in the private storage (cookie scheme.) The duplicated login is prohibited by the system and other's attempt to login to the account needs the password. Therefore, security is assured unless the user's smartphone is stolen without a screen lock.

(ii) ACT reporting function: The button at the bottom of the front page allows users to go to a page where they can report their ACT activities to other employees. On the report page, employees are encouraged to see the activities to other employees on that day. The user can report any content, official (business) or private. For each ACT report, 39 THX will be given once a day. 




Figure 2. User functions and its UI flows of the in-house currency application 
(iii) The ACT sharing and reaction functions can be launched directly from the front page of the application. On the front page, all users' ACTs for the past 30 days are displayed in a timeline format. The user can express his/her sympathy to other users' ACT posts in the timeline in three types of messages: "Like", "Wanna", and "Done."

Like: A message type to express a favorable impression of another user's ACT post.

Wanna: A message type to declare that you want to perform the same mutual aid action in response to another user's ACT post.

Done: A message type to sympathize with another user's ACT post if the user has experience in performing the same mutual aid action also.

Users' reactions for each ACT message will be counted by the application, and the total number of sympathized reactions will be displayed on the front page.

(iv) The QR code payment function can be invoked from a button on the front page as in (iii). The user scans the QR code placed at the cafeteria by the smartphone, and then enters the THX amount to be paid for the service. Finally, the user represents the payment confirmation screen to the cafeteria staff and asks him/her to push the button to complete the payment.

(v) The account management function provides the ability to change the contact e-mail address and password, as well as reset the password if it is forgotten. In addition, the user can see the list of his/her ACT reports and their reactions sent by others, with the nicknames of the top 3 responders. The user can also see the list of the user's reactions sent to others. This is designed to visualize the historical interactions with other users.

\subsection{The Functions and UI design for HR Department and IT Administrators}

(2) The functions and UI flow for the HR department and IT administrators are shown in Figure 3. The functions for administrators include (i) billing amount output function for each store, (ii) user management function, and (iii) event management function. The functions for administrators are mainly provided through a web interface for PC screens and a CLI (Command Line Interface).

(i) Store-specific invoice output function will output monthly THX sales (monthly total and daily sales details) at the concession stands and cafeterias on the company campus. Based on this function, the store to HR department will be invoiced for payment.

(ii) The user management function provides individual user status management in addition to the output of the user list and balance (on the PC Web). For individual user handling, it provides functions such as temporarily suspended users (in black-listed) who send messages that do not conform to the spirit of mutual aid.

(iii) The event management function is used in cases where the HR department particularly wants to encourage participation, such as participation in external volunteer activities or campus activation events. This function notifies the user of the event in the "Notification" column only during a specific period of time and provides an additional reward (THX) to the user who participates. 


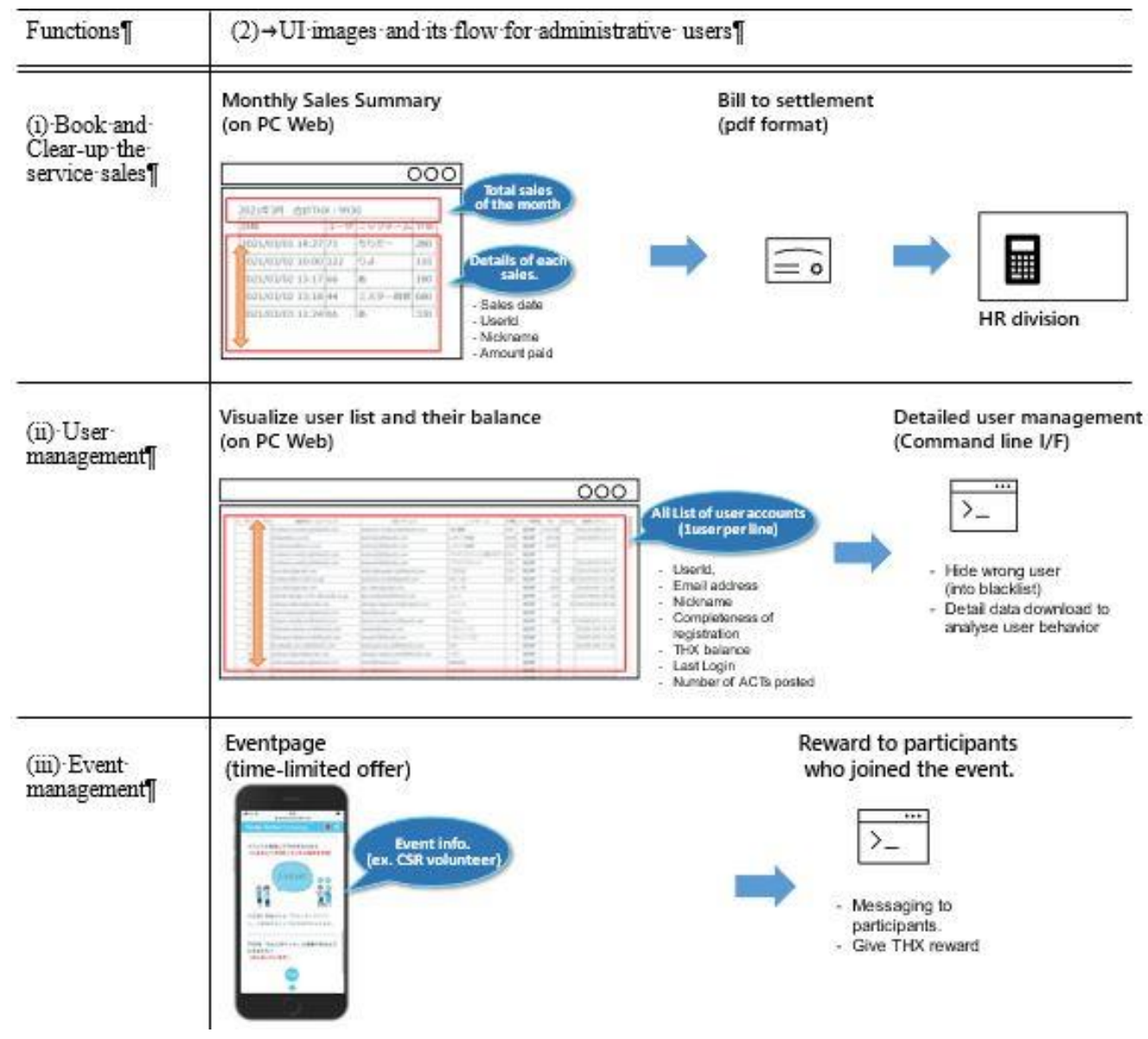

Figure 3. Administrative functions and its UI flows of the in-house currency application

\subsection{Implementation of the In-House Currency System}

We have used the AWS EC2, virtual server service (Murty, J., 2008) to build the system. The list of software used in this system is shown in Table 3. We have used t2.micro, a relatively small virtual server template, for both the AP and DB servers. For the AP server, Node.js (Tilkov, S. and Vinoski, S., 2010) and Express (Bojinov, V., 2018) framework have been used as the web server and its backend middleware, D3.js ${ }^{3}$ and jQuery (Nixon, R., 2014) as its frontend display framework. Mongo DB (Boicea, A., et al, 2012) is used as its DB server.

The schematic view of the cloud system is shown in Figure 4. The AP server mainly provides the client with a REST API to access the DB on behalf of the client, which prohibits direct DB access from the client and provides ACT registration and THX calculation and balance management on the server-side.

${ }^{3} \mathrm{http}: / / \mathrm{d} 3 \mathrm{js}$. org/ 
IADIS International Journal on WWW/Internet

The AP server also provides web server function and Client View to display the web client, which holds the html/css files (web contents) and JS (javascript) libraries inside it.

Table 3. Hardware and software specs used by the in-house currency system

\begin{tabular}{l|l|l}
\hline Server Type & Hardware specification & Software/Library used \\
\hline AP Server & $\begin{array}{l}\text { t2.micro } \\
(1 \text { vCPU, 1GB memory, 8GB SSD) }\end{array}$ & $\begin{array}{l}\text { Node.js (v4.2.6) } \\
\text { Express (v4.17.1) } \\
\text { D3.js (v4) } \\
\text { jQuery (v1.12.4) }\end{array}$ \\
\hline DB Server & $\begin{array}{l}\text { t2.micro } \\
(1 \text { vCPU, 1GB memory, 32GB SSD) }\end{array}$ & Mongo DB(v2.6.10) \\
\hline
\end{tabular}

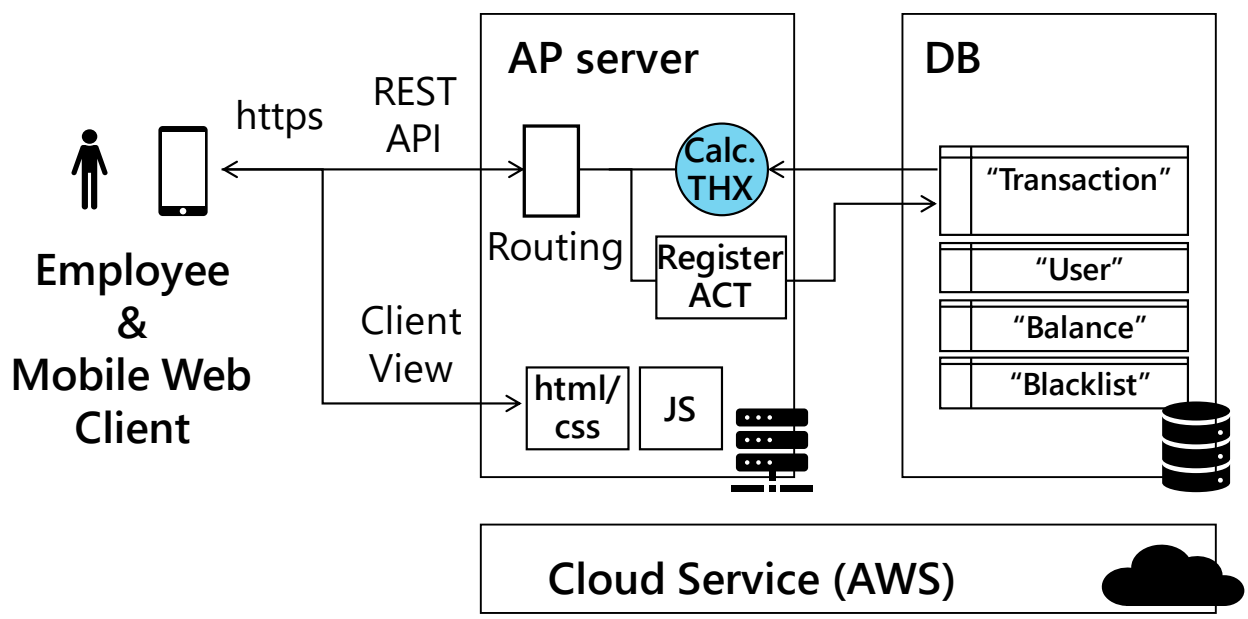

Figure 4. Block diagram of the in-house currency system

Table 4. List of REST API Interface

\begin{tabular}{l|l|l}
\hline API path & Description & $\begin{array}{l}\text { Provided API } \\
\text { types }\end{array}$ \\
\hline /login & User login & POST \\
\hline $\begin{array}{l}\text { /user } \\
\text { /user/:id }\end{array}$ & Get and Register user information. & GET/POST \\
\hline $\begin{array}{l}\text { /user/money } \\
\text { /user/money }\end{array}$ & Get the balance of THX of user. & GET \\
\hline /myself & Get the user information and update it. & GET/PUT \\
\hline /ransaction & $\begin{array}{l}\text { Get and post the ACT, Likes, and payment information to } \\
\text { the master log. }\end{array}$ & GET/POST \\
\hline
\end{tabular}

Table 4 shows a list of the REST APIs. REST APIs are designed to provide each server-side function related to the API paths. The functions are /login (User login), /user and /user/:id (Get and register user information), /user/money and /user/:id/money (Get the balance of THX of the 
user), /myself (Get the login-ed user information and update it) and /transaction (Get and posting the ACT, Likes, and payment information to the master log.)

The Provided API types are shown in Table 4 also.

The DB uses document type as its data retention format. Table 5 shows the main tables format and data example. The table is named "collection" in the case of Mongo, which is kept in the DB. The format is based on "JSON format," which is simple and easy to process by the program. JSON format helps to reduce the processing load on servers and clients, and also allows for flexible extensions of services.

Table 5. List of main DB tables

\begin{tabular}{|c|c|c|}
\hline $\begin{array}{l}\text { Table } \\
\text { Name }\end{array}$ & Description & Data property(example) \\
\hline User & User information & $\begin{array}{l}\text { \{ mail_addr : “toshiomi.moriki@yyyy.com”, } \\
\text { employee_Id: “toshiomi.moriki.xx@hitachi.com”, } \\
\text { password: “encrypted_password_strings”, } \\
\text { user_Id: 11, } \\
\text { complete: 1, } \\
\text { nickname: "MORIKI-SAN”, } \\
\text { lastLogin: } 1631185593\}, \ldots\end{array}$ \\
\hline Transfer & $\begin{array}{l}\text { Main data structure holds all } \\
\text { of the transactions (ACTs, } \\
\text { Likes, payments, etc..) }\end{array}$ & $\begin{array}{l}\text { \{type: "act", } \\
\text { amount: } 39, \\
\text { src: } 0, \\
\text { dst: } 11, \\
\text { comment: "I have helped my colleagues to open } \\
\text { new discussion thread between multiple } \\
\text { groups ;-)", } \\
\text { tx_Id: } 6225, \\
\text { unixtime: } 1631189639445\}, \ldots\end{array}$ \\
\hline Balance & $\begin{array}{l}\text { Cached data structure to keep } \\
\text { the current balance } \\
\text { information of users. }\end{array}$ & $\begin{array}{l}\text { \{ } \text { user_Id: } 11, \\
\text { balance: } 642, \\
\text { last_Updated: } 1631189639282\}, \ldots\end{array}$ \\
\hline Blacklist & $\begin{array}{l}\text { Wrong users who prohibited } \\
\text { and hidden from others. }\end{array}$ & $\{$ "user_Id" : 43$\}, \ldots$ \\
\hline
\end{tabular}

The main tables are the "User" collection which holds user information and the "Transfer" collection which holds all transactions such as ACT reports.

"User" holds user information in the form of a user in a JSON document, and contains a contact email address (mail_addr), a company email address (employee_Id) that also serves as a login ID, password information, user ID, registration completion flag (complete), nickname, and last login time (UNIX seconds).

"Transfer" holds transaction data in a JSON document, which contains whether an ACT report, a Like message, or payment information to the store. The "Transfer" table is important and keeps evidence data for all THX assignments from the administrator and payments to the stores, so only additions are allowed. The append-only data attribute is suitable to adopt the distributed DB, such as HDFS (Hadoop file system) and Blockchain data store. 
The document in the Transfer table includes the type of transaction (type), the amount of money transferred (amount), the THX sender ID (src), the THX recipient (dst), and the message string displayed on the timeline (comment), transaction serial number (tx_Id), and time when the transaction was registered (unixtime: in milliseconds).

The document in the Balance table contains the ID of the target user (user_Id), the THX balance he/she has (balance), and the time when the balance was updated (lastUpdated, in milliseconds). The current balance of the user is determined by scanning the "Transfer" log. By referring to this data structure, the scanning range of the log is limited, which improves the server performance in a shorter response time.

\section{TRIAL THE IN-HOUSE CURRENCY SYSTEM AND ITS USAGE}

Based on the design and its implementation described in Section 3, we have introduced the in-house currency system to the R\&D division where approximately 700 employees work.

The trial environment of the in-house currency system is shown in Table 6 . The test period started in April 2020, when work at the office was basically prohibited due to the declaration of a state of emergency against the spread of COVID-19.

Table 6. The trial environment of the In-house Currency System

\begin{tabular}{l|l|l}
\hline Trial Period & 2020/4/1 2021/6/30 (continued) \\
\hline \multirow{2}{*}{$\begin{array}{l}\text { Target } \\
\text { Organization }\end{array}$} & Type of organization & Research and Development \\
\cline { 2 - 3 } & \# of employees & 700 persons (approx.) \\
\cline { 2 - 3 } & Types of workers & White-collar workers \\
\hline \multirow{3}{*}{ Incentive Setting } & Incentive Amount & 39 THX per ACT (once a day rewarded) \\
\cline { 2 - 3 } & Peer Bonus Amount & 1 THX per Like (no limitation per day) \\
\cline { 2 - 3 } & $\begin{array}{l}\text { Incentive Amount for Inviting a new } \\
\text { user }\end{array}$ & 110 THX per program. \\
\cline { 2 - 3 } & Where to use & In-house store and cafeteria \\
\hline
\end{tabular}

In the trial, we conducted three promotion methods: (a) to improve user recognition at the time of service launch, (b) to recruit users by word of mouth, and (c) to encourage out-of-job activities led by the HR department.

For method (a), in addition to explanations on the intranet, we made and displayed posters and instructions at easily visible locations as shown in Figure 5. In particular, the philosophy of spreading mutual help among employees was disseminated, and simple instructions were frequently provided to overcome barriers to use. 


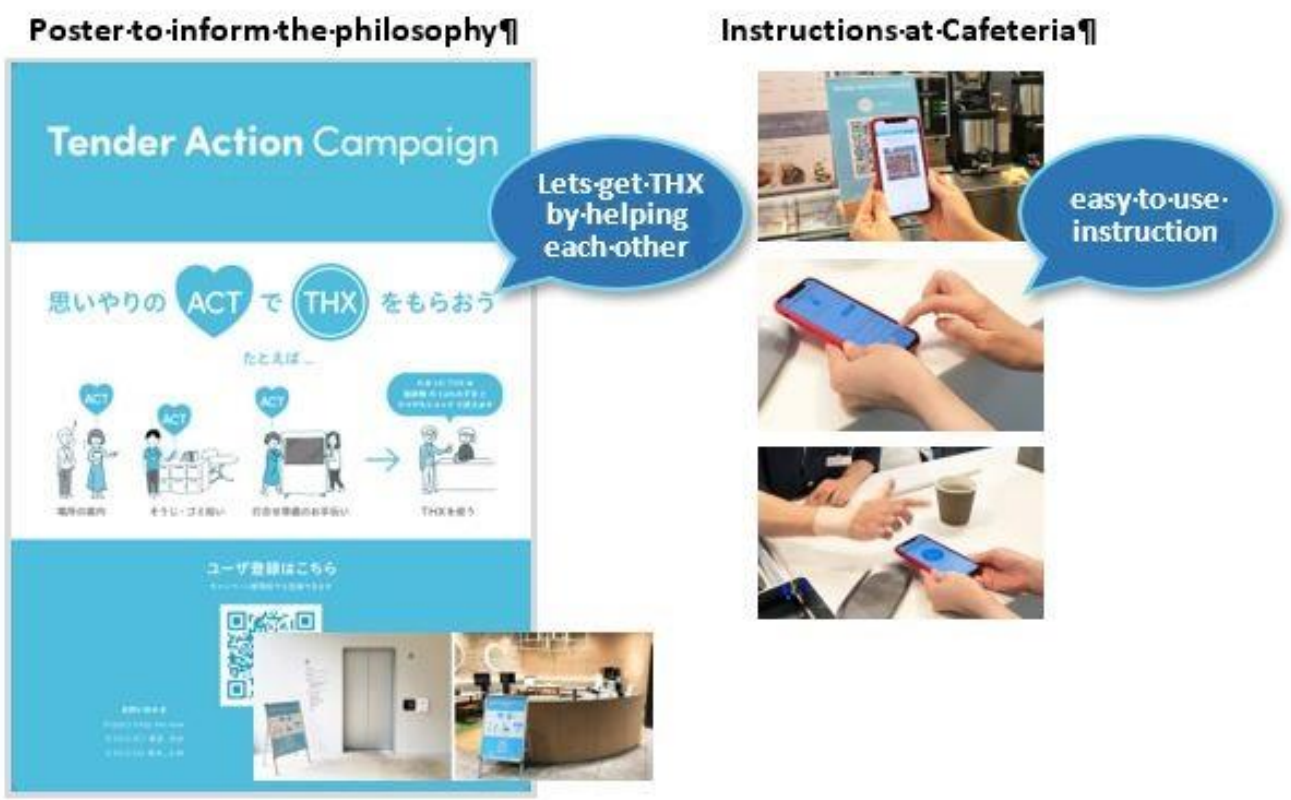

Figure 5. (a) Promotion methods at the early phase

As for measure (b), we developed a function to promote the solicitation of new employees from users who have already used the system and its promotion. The invitation incentive is 110 THX for each inviter and invitee. 110 THX is a small incentive equivalent to a cup of coffee.

For measure (c), the campaign was executed by the HR department after a certain number of users had been acquired, mainly to promote volunteer and CSR activities outside of work and to increase employee engagement. Table 7 shows the activities for which THX payments were made.

Table 7. (c) HR led campaigns to encourage volunteering and CSR activities

\begin{tabular}{l|l|l|ll}
\hline$\#$ & Activities & Description & $\begin{array}{l}\text { Paid amount of } \\
\text { THX }\end{array}$ \\
\hline 1 & $\begin{array}{l}\text { Video contents for } \\
\text { societal PR of the } \\
\text { company }\end{array}$ & $\begin{array}{l}\text { Internal solicitation of materials (mainly } \\
\text { photos) to be used in a video introducing the } \\
\text { nature and environment of the company } \\
\text { campus. }\end{array}$ & $\begin{array}{l}110 \text { THX per } \\
\text { content }\end{array}$ \\
\hline 2 & $\begin{array}{l}\text { Food donation activities } \\
\text { for the local community }\end{array}$ & $\begin{array}{l}\text { Collection of surplus household food and old } \\
\text { postage stamps for CSR (donated to welfare } \\
\text { organizations in the city) }\end{array}$ & $\begin{array}{l}110 \text { THX per } \\
\text { donation }\end{array}$ \\
\hline 3 & $\begin{array}{l}\text { Reporting personal } \\
\text { volunteer activities }\end{array}$ & $\begin{array}{l}\text { Self-reporting of volunteer activities for } \\
\text { individual participation (activities in FY2020 } \\
\text { can be reported) }\end{array}$ & 110 THX per report \\
\hline
\end{tabular}


IADIS International Journal on WWW/Internet

Table 8 shows the transition of the status of user involvement during the trial operation period. The user status is tracked by following 4 stages:

(i) Aware of this service:

They can see the announcement of the in-house currency system introduced. (It is assumed all of the employees in this office were got this announcement via intranet and on-the-site messaging.)

(ii)

Registered as a User:

They have been registered by their email address and their password via the smartphone application.

(iii) Reported ACT and Earn THX:

They have reported their ACT once or more, and they have earned THX points.

(iv) Share the Service Actively:

They have invited new users actively and the invitees have registered to this system.

In the first 2-month of the trial period, the state of emergency corresponding to the infectious disease epidemic was declared (from April 1 to May 27). The office of the trial target organization was almost in a state of lockdown. Although almost all of the employees were working from home and away from their office, the number of users registered in stage (ii) and ACT-reported users in stage (iii) increased rapidly just after the service was launched. The number in stage (ii) increased to 84 and the ACT-reported users in stage (iii) was 55 as of May 27. It is thought that effective advertising and promotion measures (a) were carried out.

After that, telecommuting was half enforced until the end of July, but from August 5, (b) the program to recruit new users was started. In October, (c) several timed programs were conducted led by the administration department (HR) in order to encourage employees' volunteer and CSR activities. In stage (iv), 7 users eventually shared and spread the program to other users. They have contributed to the acquisition of a total of 22 new users of the stage (ii), from 104 to 126.

Table 8. Transition of user engagement status

\begin{tabular}{l|c|c|c|c}
\hline Date & $\begin{array}{c}\text { (i) Aware to this } \\
\text { Service }\end{array}$ & $\begin{array}{c}\text { (ii) Registered as a } \\
\text { User }\end{array}$ & $\begin{array}{c}\text { (iii) Reported } \\
\text { ACT and Earn } \\
\text { THX }\end{array}$ & $\begin{array}{c}\text { (iv) Share the } \\
\text { Service Actively }\end{array}$ \\
\hline $2020 / 4 / 1$ & 700 & 17 & 5 & 0 \\
\hline $2020 / 5 / 27$ & 700 & 84 & 55 & 0 \\
\hline $2020 / 8 / 5$ & 700 & 92 & 57 & 0 \\
\hline $2020 / 10 / 14$ & 700 & 104 & 60 & 7 \\
\hline $2021 / 3 / 29$ & 700 & 118 & 61 & 7 \\
\hline Note & 700 & $\begin{array}{c}\text { \# of users } \\
\text { registered. }\end{array}$ & $\begin{array}{c}\text { \# of users } \\
\text { reported an ACT } \\
\text { or more. }\end{array}$ & $\begin{array}{c}\text { \# of users } \\
\text { invited new } \\
\text { users. }\end{array}$ \\
\hline
\end{tabular}

Figure 6 shows the trends of the number of users in each stage during the trial period of the in-house currency system.

The number of users in stage (ii) who completed the registration reached 84 within the first month of the test introduction of the in-house currency system. This result indicates that the 
initial measures (a) to improve user recognition and understandings by posters and instructions to the system have been generally successful. After that, the number of users in stage (ii) increased steadily thanks to (b) the program for new user invitations and (c) HR-led campaigns, and finally 126 users were acquired.

The number of users in stage (iii), who reported an ACT once or more, reached 55 at the end of the emergency declared period, the end of May. On the other hand, the number of users in stage (iii) after May did not grow much compared to stage (ii), and it turned out that almost half of the registered users had never reported an ACT finally. This implied that the users might be fixed who reports ACTs and sends Likes repeatedly.

The users on stage (iv): sharing and spreading, are limited throughout the trial period. By (b) the program for new user invitation, 110 THX is offered to both new registrants and solicitors as rewards for solicitation but it would not work effectively. For getting more employees to use this system, it might be necessary to take further promotions including advertising measures.



Figure 6. Trends of the number of users in each stage 


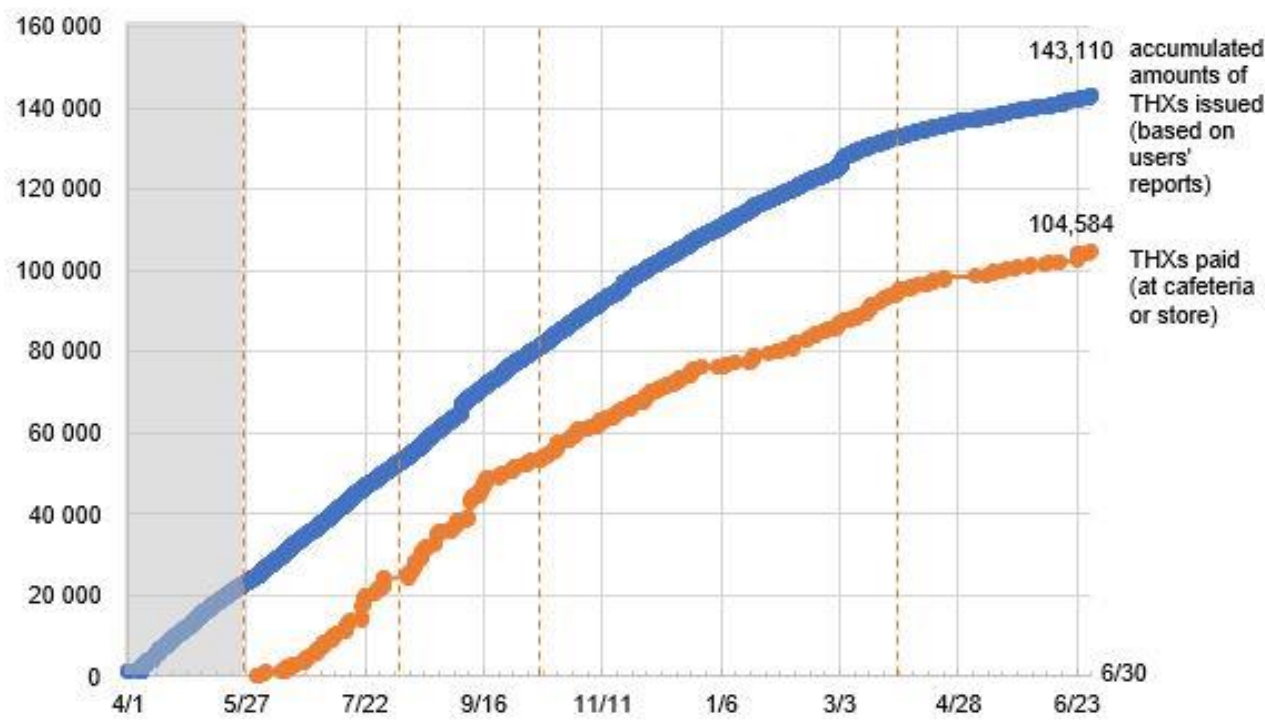

Figure 7. Trends of accumulated THXs issued and paid by the in-house currency system

Figure 7 shows the trend of THX issuance and paid by users throughout the experimental period. Throughout the experimental period, users reported ACTs stably, and the issuance of THX increased almost linearly. The company paid out 366 THX per day on average, which means that 9 to 10 people reported their ACTs. Payments by users at the cafeteria and concession stands have been made since Jun. 2020, after the state of emergency, was lifted.

The payments have been made sequentially following the issuance of THX, but some of the payments are still pending and have not been paid from user accounts. As a result of the user interviews, some users answered that they look forward to acquiring THX itself, and user preferences may be leading to the withdrawal of THX.

Figure 8 shows the frequency distribution of the price per unit of THX acquisition and payment by users. While $39 \mathrm{THX}$ /day was used in most cases for THX acquisition, some users were paid a higher price due to the timed program (c) for acquiring new users and interviews with users about their usage. In addition, since many users reported ACTs with THX=0 (i.e., more than two reports per day), employees desire to report each other's supportive behavior even when there is no monetary reward. 


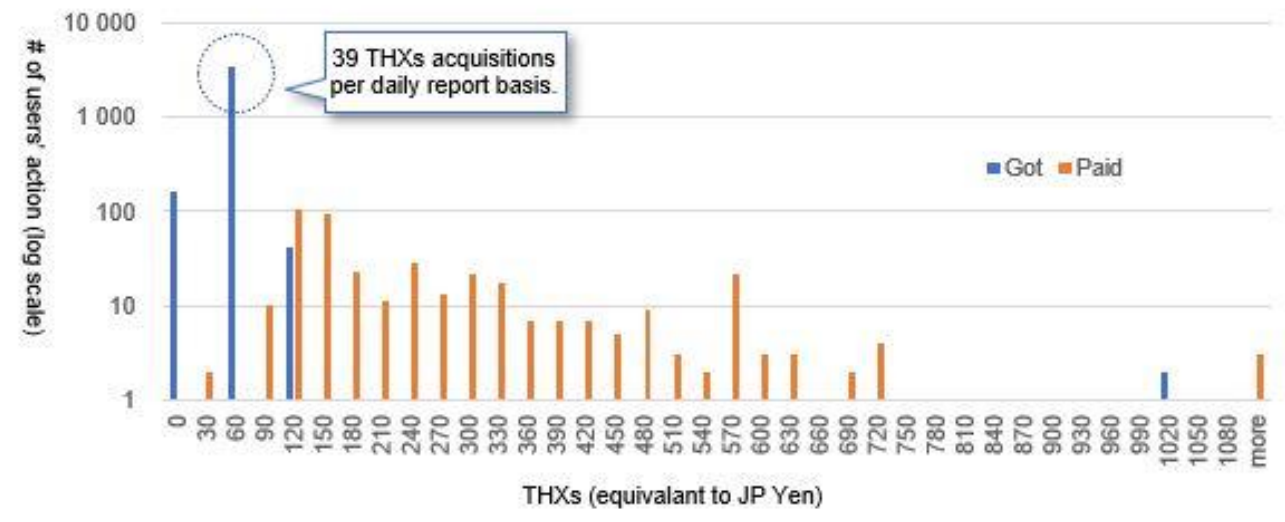

Figure 8. THX amounts per each action (got or paid)

Payments at the cafeteria and store peaked between 120 and 150 THX continued to grow steadily thereafter to around $570 \mathrm{THX} /$ payment. This suggests that users are making THX payments for every 3 to 10 or more ACT reports.

Table 9. Summary of the results of the user interviews

\begin{tabular}{|c|c|c|}
\hline & $\begin{array}{l}\text { Feedbacks from general users } \\
\qquad(\mathrm{N}=6)\end{array}$ & $\begin{array}{l}\text { Feedbacks from } \mathrm{HR} \text { and IT } \\
\text { administrative staffs }(\mathrm{N}=4)\end{array}$ \\
\hline $\begin{array}{l}\text { Positive } \\
\text { opinions }\end{array}$ & $\begin{array}{l}\text { - It's nice to know that other employees } \\
\text { are working well in this company too. } \\
\text { (It makes me feel not alone, } \\
\text { especially during the lockdown } \\
\text { period.) } \\
\text { - } \quad \text { feel motivated to do my best when I } \\
\text { get "Likes". (It satisfies my self- } \\
\text { efficacy.) } \\
\text { The system makes it easier for me to } \\
\text { buy additional cups of coffee for my } \\
\text { colleagues. It's a good conversation } \\
\text { starter. }\end{array}$ & $\begin{array}{l}\text { This is effective in fostering a } \\
\text { volunteer mindset among } \\
\text { employees. } \\
\text { - It promotes communication } \\
\text { among employees. } \\
\text { - The system is not too difficult } \\
\text { to use. It does not require a lot } \\
\text { of effort for user support. }\end{array}$ \\
\hline $\begin{array}{l}\text { Negative } \\
\text { opinions }\end{array}$ & $\begin{array}{l}\text { - It is disappointing to see wrong ACTs } \\
\text { on the timeline of others, for example, } \\
\text { who always write too short or canned } \\
\text { messages. } \\
\text { The ways to use THX are limited in } \\
\text { the office, so it is preferable to get new } \\
\text { ways to use it when I work from home } \\
\text { (WfH.) }\end{array}$ & $\begin{array}{l}\text { - The users who use the in-house } \\
\text { currency on a daily basis tend to } \\
\text { be constant. } \\
\text { - } \quad \text { Since nicknames are used upon } \\
\text { the system, exchanges on the in- } \\
\text { house currency system do not } \\
\text { lead to direct business benefits. }\end{array}$ \\
\hline
\end{tabular}


IADIS International Journal on WWW/Internet

During the trial period, interviews were conducted with general users and staff from the HR and IT management departments regarding the system. A summary of the interview results is shown in Table 9. There were six interviewees from the general users and four interviewees from the HR and IT management departments.

The positive feedback from the general users was that they were happy to know that other employees were working as well as they were. In particular, many employees suffer from loneliness during the lockdown period, and it is assumed that communication through the in-house currency system became a refreshing distraction. Other comments were that receiving "Likes" boosted their sense of self-affirmation and that it provided an opportunity to talk with colleagues when using the cafeteria.

Negative comments included that it is disappointing to see very short or canned messages from other users on the timeline and that THX can only be used in the office, so they would like a way to use it when working from home.

Positive comments expressed by the HR and IT management staff included that the system was useful in fostering a volunteer mindset among employees and that it helped to stimulate communication among employees. They also commented that the system was not excessively difficult and that user support was easy. One negative comment was that the users of the in-house currency THX tended to be fixed. Some users also pointed out that since they communicate using nicknames, interactions on the system do not directly lead to business benefits. Based on these comments, we are planning to make further improvements to the UI and system.

\section{CONCLUSION}

The design and the implementation of an in-house currency system are proposed. The system has two series of user interfaces; one UI is for the general users by smartphone mobile web application and another UI is for HR and IT administrative staff by PC web and command-line interface. The system implementation is mainly based on cloud computing services and OSS software, with a two-tiered AP/DB structure, and DB server access is designed via a REST API to ensure service independence, scalability, and security.

By the analysis of the 15-month trial log for our R\&D department, it is found that more than $70 \%$ of users registered in the first two months, despite the declared state of emergency. Subsequent user acquisition programs, off-the-job volunteer activities, and other activation measures have resulted in continuous user engagement.

Deep interviews with general users and administrative staff suggested that the system was effective in stimulating communication among employees and improving their self-efficacy in a work environment where they were forced to work remotely during the pandemic. In addition, the UI was not overly difficult and was appropriate for both user usage and support. On the other hand, some points for improvement were found, such as the handling of inappropriate messages shared on the timeline and the limited use of the in-house currency THX. 


\section{REFERENCES}

Boicea, A., et al, 2012. MongoDB vs Oracle--database comparison, In Proc. of 2012 third International Conference on Emerging Intelligent Data and Web Technologies, IEEE, pp.330-335.

Bojinov, V., 2018. RESTful Web API Design with Node. js 10: Learn to create robust RESTful web services with Node. js, MongoDB, and Express.js. Packt Publishing Ltd.

Moriki, T., et al, 2021. MEASURING THE ENGAGEMENT OF IN-HOUSE CURRENCY SYSTEM USERS. In Proceedings of 14th International Conferences ICT, Society, and Human Beings, pp.3-10.

Morris, B., 2020. Why does Zoom exhaust you? Science has an answer. accessed 15 Sep. 2021, https://www.wsj.com/articles/why-does-zoom-exhaust-you-science-has-an-answer-11590600269

Murty, J., 2008. Programming amazon web services: S3, EC2, SQS, FPS, and SimpleDB. O'Reilly Media, Inc.

Nishida, Y. and Terashima, N., 2019. Japanese work style and "Work-style reform" : The problem of reducing long working hours and introducing telework. Psychologist: bulletin of the Graduate School of Professional Clinical Psychology, Kansai University, (9), pp 61-69. (in Japanese)

Nixon, R., 2014. Learning PHP, MySQL \& JavaScript: With jQuery, CSS \& HTML5. O'Reilly Media, Inc.

Slack, 2018. The Business Value of Slack. accessed 15 Sep. 2021, https://a.slack-

edge.com/eaf4e/marketing/downloads/resources/IDC_The_Business_Value_of_Slack.pdf

Tamura, K., 2018. Eliminating waste and optimizing manpower and equipment! DISCO's mysterious "in-house currency operation". Nikkei Top Leader, 402, pp.76-82. (in Japanese)

Tilkov, S. and Vinoski, S., 2010. Node. js: Using JavaScript to build high-performance network programs. IEEE Internet Computing, 14(6), pp.80-83.

Wang, B., et al, 2021. Achieving effective remote working during the COVID - 19 pandemic: A work design perspective. Applied psychology. 70(1), pp.16-59. 